\title{
Visual measurements and spectral survey of night sky brightness in Venezuela and Italy
}

\author{
F. Della Prugna ${ }^{1,2}$ \\ ${ }^{1}$ Centro de Investigaciones de Astronomía CIDA, A.P. 264, 5101-A Mérida, Venezuela \\ ${ }^{2}$ Dipartimento di Fisica, Università di Siena, Via Banchi di Sotto, 55 - 53100 Siena, Italy
}

Received May 28; accepted September 9, 1999

\begin{abstract}
This paper reports measurements of zenith night sky brightness and a spectral survey carried out at selected places in Venezuela and Italy. These range from large cities (Caracas and Florence) and towns (Mérida and Siena), to dark sites, such as the Venezuelan Astronomical Observatory and the Alps. Measurements were carried out visually by means of a simple photometer and spectra from 4100 to $6400 \AA$, were obtained by a small spectrograph. From the results obtained at the sites tested in Italy, the sky brightness increase since 1973 is given. Since in both countries there are effective regulations to fight light pollution, and more are foreseen in the near future, it is the purpose of this paper to stress the importance, and also the need, of night sky quality monitoring over time to assess the efficacy of these legal tools.
\end{abstract}

Key words: site testing — techniques: photometric techniques: spectroscopic

\section{Introduction}

The diffuse brightness of the moonless night sky is produced by natural and artificial sources. Natural processes include airglow, tropospheric scattering of starlight, light from faint stars and the zodiacal light. Updated levels of natural sky brightness have been reported by Leinert et al. (1998) and Schaefer (1998).

On the other hand, artificial night sky brightness is due to man-made lighting systems that, unfortunately, also illuminate the sky, both directly and by single or multiple reflections from the ground and buildings. Both natural and artificial sources are variable. It is well known, for instance, that airglow emissions vary according to changes in the upper atmosphere and the solar cycle.

Send offprint requests to: F. Della Prugna
Unlike the natural change of night sky brightness, which at some point eventually returns to a minimum, light pollution has increased steadily over time. Even the casual observer is able to realize that the night sky is much brighter now than in the past. This issue has concerned not only the astronomical community but also common citizens, at the point that several regulations are currently in effect to protect sky conditions at major observatories and at special sites, such as natural parks and reservations.

Nevertheless, the efficacy of these and future regulations can only be assessed by the direct monitoring of the night sky quality over time. This is usually carried out at most observatories, but measurements of night sky brightness at other common places, such as cities, towns and villages, which represent the main polluting sources, are scarce. In Venezuela, measurements of night sky brightness have been carried out at the Venezuelan Astronomical Observatory (VAO) only recently. Located near the equator at an altitude of $3600 \mathrm{~m}$ in the Andes, the VAO is protected by a recent regulation (Gaceta Oficial 1991), intended to minimize light pollution in its vicinity. In Italy, the first light pollution map of the territory was compiled by Bertiau et al. (1973). At present, several regional laws regulate local lighting systems and a national law is being discussed (Cinzano 1997).

Since these legal tools will hopefully reduce, or at least stop, light pollution and improve artificial lighting standards, this paper reports recent zenith night sky brightness at selected places in Venezuela and Italy, including large cities, town and villages, with the aim to provide reference values that can be used for future comparisons and also to test the feasibility of night sky brightness predictions using satellite images of the Earth at night.

At the same time, a small spectrograph was used to take representative spectra of the night sky from about 4100 to $6400 \AA$. This is because forty years ago public lighting relied basically on incandescent lamps; these have a continuum spectrum corresponding, essentially, to a blackbody source at $2600 \mathrm{~K}$. Nowadays, the majority of 


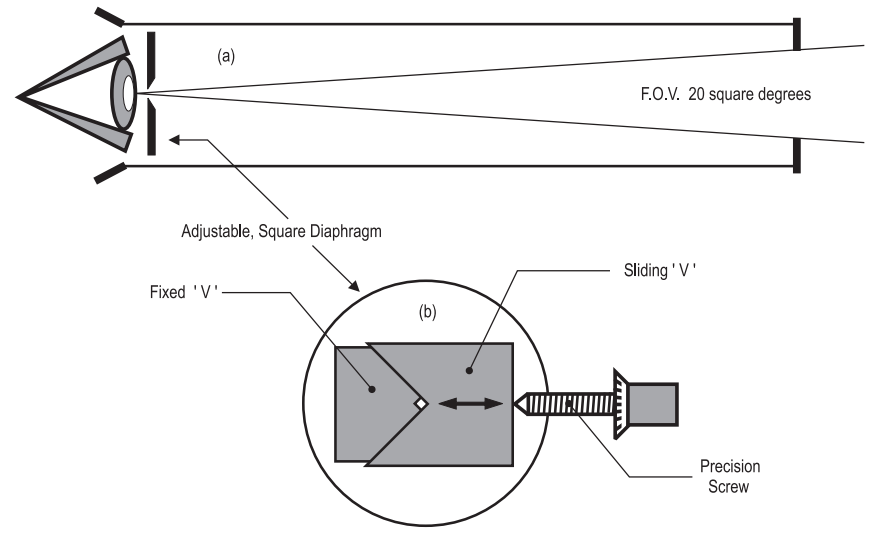

Fig. 1. Schematic view of the Visual Photometer (VP). a) Cut away of the device. b) Details of the adjustable, square diaphragm

the lamps used in public lighting are of the gas discharge type, namely High Pressure Sodium and Mercury, with strong emission lines in their spectra. For this reason, a more comprehensive description of night sky conditions is given not only by the zenith brightness, but also by the spectral distribution of the light that pollutes the sky at a specific site.

\section{The visual photometer}

While photoelectric photometers and CCDs are readily available at most observatories to monitor night sky brightness, these instruments are rarely made for field use, since it is usually impractical to transport the associated electronics and computers. Nevertheless, small, portable photoelectric photometers have been especially constructed to measure night sky brightness (Treanor \& Salpeter 1972; Walker 1973).

On the other hand, portable, visual photometers have been successfully used to measure night sky brightness with a precision of 10\% (0.1 mag), (Berry 1976; Pike \& Berry 1978). The visual photometer (VP) used in the observing campaign reported here is very simple. It consists of two plastic tubes, about $25 \mathrm{~cm}$ long and fully blackened inside, coupled together. One of them is closed; the other has a circular aperture at the end facing the sky and an adjustable, square diaphragm at the other end, just in front of the observer's eye (Fig. 1). This diaphragm opens continuously, from totally closed to about one square millimeter, by means of a calibrated precision screw. In this way, the open area of the diaphragm can be easily determined. When the observer looks through this device with the diaphragm totally open, a circular patch of sky of about 20 square degrees can be seen in one eye. The other eye is not used but can be left open since the corresponding tube is closed. Also, stray light is kept at a minimum by using rubber eyeguards around the tubes. Curiously, mild, refractive visual defects, such as myopia or hypermetropia, do not hamper measurements, since the small opening of the diaphragm in front of the observer's eye greatly increases its focus depth. To carry out a measurement the observer, with dark adapted eyes and using averted vision, closes the adjustable diaphragm until the patch of the sky seen through the VP is barely visible. The brighter the sky, the lesser is the diaphragm opening to reach this condition. At this point, the sky has been dimmed to the threshold of scotopic (dark adapted) vision for a uniform continuous source, which corresponds for the normal eye to about $27.0 \mathrm{mag} / \operatorname{arcsec}^{2}$ (Allen 1973). This dimming can be expressed in magnitudes:

$A=-2.5 \log (D / P)$

where $A$ is the magnitude attenuation, $D$ is the area of the diaphragm and $P$ is the area of the pupil of the dark adapted eye. $P$ is arbitrarily set to $38.48 \mathrm{~mm}^{2}$, corresponding to a normal pupil diameter of $7 \mathrm{~mm}$. Subtracting $A$ from the scotopic threshold, we obtain the sky brightness in units of mag/arcsec ${ }^{2}$. Of course, the scotopic threshold differs from observer to observer and it could also depend on the observer's age.

\section{Tests and calibration}

To determine the internal precision of the combination VP-Observer, a long term test was carried out. Measurements of a constant, uniformly illuminated surface corresponding to a sky brightness of about $21.0 \mathrm{mag} / \operatorname{arcsec}^{2}$ taken over a six-month period, show a rms scatter of 0.05 magnitudes. This value seems to indicate a good eye threshold constancy over long periods of time. Nevertheless, experience suggests that, under typical field conditions, night sky brightness can be measured with a precision of 0.1 mag.

On the other hand, calibration of VP-Observer was performed by simultaneous measurements of night sky brightness using both the VP and CCDs (broadband $V$ photometry). This is necessary because the personal eye threshold may differ from the typical value. This procedure should also account for invisible faint stars that nonetheless contribute to the sky background. The necessary corrections are included in the personal zero point (ZP). A journal of CCD observations for zero point calibration is given in Table 1. Results from aperture photometry show that the author's mean zero point is $27.2 \mathrm{mag} / \operatorname{arcsec}^{2}$. Thus, sky brightness is found subtracting A, given by Eq. (1), from this value, this is:

$m_{\mathrm{sky}}=Z P-A$

where $m_{\text {sky }}$ is the sky brightness in mag/arcsec ${ }^{2}, Z P$ is the personal zero point and $A$ is the magnitude attenuation measured by the VP. No colour terms were included in Eq. (2). A yellow filter, such as Wratten No. 15, rejecting the blue wing, could probably improve the spectral band consistency, but this must be confirmed experimentally to justify its use. 
Table 1. Journal of $V$, CCD observations for personal zero point calibration

\begin{tabular}{|c|c|c|c|c|c|}
\hline $\begin{array}{c}\text { Telescope dia. }[\mathrm{cm}] \\
\text { Site }\end{array}$ & $\begin{array}{c}\text { Field } \\
\text { Center }\end{array}$ & $\begin{array}{c}\text { Total } \\
\text { Extinction } \\
{[\mathrm{mag}]}\end{array}$ & $\begin{array}{c}\text { Sky } \\
\text { brightness } \\
{\left[\mathrm{mag} / \mathrm{arcsec}^{2}\right]}\end{array}$ & $\begin{array}{c}\text { VP } \\
\text { Attenuation } \\
{[\mathrm{mag}]}\end{array}$ & $\begin{array}{c}\text { Zero } \\
\text { Point } \\
{\left[\mathrm{mag}_{\mathrm{arcsec}^{2}}\right]}\end{array}$ \\
\hline $\begin{array}{c}15.5 \\
\text { Balma Lodge }\end{array}$ & $\begin{array}{c}\text { R.A. } 18^{\mathrm{h}} 12^{\mathrm{m}} \\
\text { Dec. }+41^{\circ} 50^{\prime}\end{array}$ & 0.24 & 21.2 & 6.0 & 27.2 \\
\hline $\begin{array}{c}25.5 \\
\text { Torre Luciana Obs. }\end{array}$ & $\begin{array}{c}\text { R.A. } 18^{\mathrm{h}} 12^{\mathrm{m}} \\
\text { Dec. }+41^{\circ} 50^{\prime}\end{array}$ & 0.36 & 20.1 & 7.1 & 27.2 \\
\hline 100 & $\begin{array}{c}\text { R.A. } 15^{\mathrm{h}} 39^{\mathrm{m}} \\
\text { Dec. }+0^{\circ} 15^{\prime}\end{array}$ & 0.16 & 21.1 & 6.0 & 27.1 \\
VAO & & \multicolumn{2}{|l}{} \\
\hline
\end{tabular}

Table 2. Zenith night sky brightness at selected sites in Venezuela and Italy. Typical values refer to the mode of the distribution

\begin{tabular}{|c|c|c|c|c|}
\hline $\begin{array}{c}\text { Site } \\
\text { (Latitude, Longitude, Altitude, Population) }\end{array}$ & Date & $\begin{array}{l}\text { [mag } \\
\text { typ. }\end{array}$ & $\begin{array}{r}\left.\sec ^{2}\right] \\
\min \end{array}$ & $\begin{array}{c}\text { Sky brightness } \\
\text { increase since } 1973 \\
{[\mathrm{mag}]} \\
\end{array}$ \\
\hline $\begin{array}{c}\text { Caracas } \\
10^{\circ} 30^{\prime} 4 \mathrm{~N}, 66^{\circ} 54^{\prime} 1 \mathrm{~W}, 900 \mathrm{~m}, 1822000 \\
\end{array}$ & 28, 30 Nov. 1997 & 18.0 & - & - \\
\hline $\begin{array}{c}\text { Mérida } \\
8^{\circ} 35^{\prime} .5 \mathrm{~N}, 71^{\circ} 8^{\prime} .6 \mathrm{~W}, 1500 \mathrm{~m}, 171000\end{array}$ & $\begin{array}{c}\text { 22 Jan. } 1999 \\
\text { 20, } 21 \text { Feb. } 1999\end{array}$ & 19.6 & - & - \\
\hline $\begin{array}{l}\text { El Valle (Mérida) } \\
8^{\circ} 39^{\prime} \cdot 7 \mathrm{~N}, 71^{\circ} 6.5 \mathrm{~W}, 2000 \mathrm{~m},-\end{array}$ & $\begin{array}{c}19,23,24,25,29 \text { Oct. } 1997 \\
3,22 \text { Nov. } 1997 \\
\text { 20, 21, } 23,25 \text { Dec. } 1997 \\
\text { 4 Jan. } 1998 \\
\text { 17, } 21 \text { Oct. } 1998\end{array}$ & 20.7 & 20.9 & - \\
\hline $\begin{array}{c}\mathrm{VAO} \\
8^{\circ} 47^{\prime} .3 \mathrm{~N}, 70^{\circ} 52^{\prime} .0 \mathrm{~W}, 3600 \mathrm{~m},-\end{array}$ & $\begin{array}{c}6,17,18,24 \text { Nov. } 1997 \\
\text { 27 Jan. } 1998 \\
\text { 16 Oct. } 1998 \\
18 \text { Dec. } 1998\end{array}$ & 21.1 & 21.3 & - \\
\hline $\begin{array}{c}\text { Florence } \\
43^{\circ} 46^{\prime} \cdot 5 \mathrm{~N}, 11^{\circ} 15^{\prime} \cdot 0 \mathrm{E}, 49 \mathrm{~m}, 402000 \\
\end{array}$ & $\begin{array}{l}\text { 26, } 27 \text { Aug. } 1998 \\
19 \text { Sep. } 1998 \\
\end{array}$ & 17.5 & - & 1.4 \\
\hline $\begin{array}{c}\text { Luciana (Florence) } \\
43^{\circ} 36^{\prime} 6 \mathrm{~N}, 11^{\circ} 16^{\prime} \cdot 1 \mathrm{E}, 401 \mathrm{~m},-\end{array}$ & $\begin{array}{l}\text { 19, } 26 \text { May } 1998 \\
\text { 16 Jun. } 1998 \\
\text { 16 Jul. } 1998 \\
\text { 26, 27 Aug. } 1998\end{array}$ & 20.1 & 20.3 & 0.7 \\
\hline $\begin{array}{c}\text { Siena } \\
43^{\circ} 19^{\prime} \cdot 0 \mathrm{~N}, 11^{\circ} 19^{\prime} 9 \mathrm{E}, 345 \mathrm{~m}, 57000\end{array}$ & $\begin{array}{l}15 \text { Jul. } 1998 \\
14 \text { Aug. } 1998\end{array}$ & 19.3 & - & 1.6 \\
\hline $\begin{array}{c}\text { Le Tolfe (Siena) } \\
43^{\circ} 20^{\prime} 8 \mathrm{~N}, 11^{\circ} 20^{\prime} \cdot 3 \mathrm{E}, 330 \mathrm{~m},-\end{array}$ & $\begin{array}{c}1,17,19,20,21,24,25 \text { Apr. } 1998 \\
\text { 17, 22, 30 May } 1998 \\
\text { 22 Jun. } 1998 \\
\text { 15 Jul. } 1998 \\
\text { 24 Aug. } 1998\end{array}$ & 20.0 & 20.3 & - \\
\hline $\begin{array}{c}\text { S. Omero (Teramo) } \\
42^{\circ} 47^{\prime} \cdot 2 \mathrm{~N}, 13^{\circ} 48^{\prime} \cdot 1 \mathrm{E}, 217 \mathrm{~m}, 5300\end{array}$ & $\begin{array}{c}\text { 29,30 Mar. } 1998 \\
\text { 21, 22, 23 Aug. } 1998\end{array}$ & 19.2 & 19.7 & 2.1 \\
\hline $\begin{array}{l}\text { Balma Lodge (Cuneo) } \\
44^{\circ} 13^{\prime} \cdot 9 \mathrm{~N}, 7^{\circ} 45^{\prime} .0 \mathrm{E}, 1883 \mathrm{~m},-\end{array}$ & 24, 25, 26, 27 Jul. 1998 & 20.9 & 21.2 & 0.6 \\
\hline
\end{tabular}

\section{Measurements}

Measurements of night sky brightness in Venezuela were carried out from October 1997 to March 1998 and from October 1998 to February 1999. In Italy, a six-month, uninterrupted observing campaign started on April 1998. Results are summarized in Table 2. Values refer to zenith brightness on moonless, clear nights. The latter is very important, since effects from the scattering layer depend strongly on transparency. However, on exceptionally clear nights, especially in winter, measurements show that sky brightness can be 0.3 magnitude fainter than typical values. Also, special care was used to select a patch of sky far from the Milky Way and the Ecliptic. At the same time, before a reading could be taken, at least 20 minutes in subdued light were spent to reach a good level of dark adaptation. This is sometimes troublesome when the observer is near bright sources, as is the case in inhabited centers. In this situation, it is very useful to wear special, deep-red goggles in order to preserve the eyes dark 
adapted. A measurement comprises three to five consecutive readings of the sky brightness. The mean is reported in a special form that must be also filled with relevant data such as the site name, date, local time and a brief description of sky conditions. Measurements at Caracas, Mérida, Florence and Siena were carried out from downtown areas.

\section{Discussion}

The sites tested span from heavily polluted to dark skies. Caracas and Florence show obviously the brightest values. Nevertheless, in spite of the fourfold factor in population compared to Florence, the typical night sky at Caracas is 0.5 magnitude darker. This is due to the smaller number of lamps per capita, and also because of the moderately high altitude of Caracas $(900 \mathrm{~m})$. Mérida, Siena and S. Omero show almost the same light pollution level, once again, with a wide range of inhabitants. S. Omero has a remarkable high level, considering its small population. Located a few kilometers from the town of Teramo, this village is however surrounded by many polluting sources. Probably, its proximity to the Adriatic coast, heavily illuminated at night, contributes strongly to the high level found. Le Tolfe is a residential zone about 4 kilometers away from downtown Siena. Luciana, many years ago an inhabited small village near Florence, is the site of the Torre Luciana Observatory, a small facility operated by the Physics Department of the University of Siena. In spite of its proximity to Florence, and excluding the northern horizon, which is completely flooded by lights from this city, the zenith sky brightness is not so high. El Valle, located 6 kilometers from the town of Mérida, shows a sky approximately one magnitude brighter than the typical dark, natural sky. Finally, the least polluted skies were found on the Italian Alps, at La Balma lodge, and at the Venezuelan Astronomical Observatory in the Andes. Nevertheless, even at these sites, a mild level of light pollution is evident.

Thanks to earlier maps of sky brightness in Italy, calculated by Bertiau et al. (1973), it has been possible to estimate the increase of light pollution over 25 years at the sites tested. The maps produced by these authors show sky magnitudes in the $B$ band. To allow a comparison, the colour index of the polluting light must be known. From photoelectric observations by Walker (1973), carried out in California and Arizona the same year, a colour index $B-V=1.2$ can be calculated. Assuming a similar spectral distribution in Italy in 1973, $B$ values from Bertiau were converted to $V$ magnitudes and the comparison followed. This is shown in the last column of Table 2. It is clear that the increase of light pollution in inhabited centers is not directly related to the population growth over 25 years. Recently, Falchi \& Cinzano (1998), by means of satellite images, synthesized a new light pollution map of the italian territory. The sky brightness values reported in Table 2 seem to confirm their forecasts.

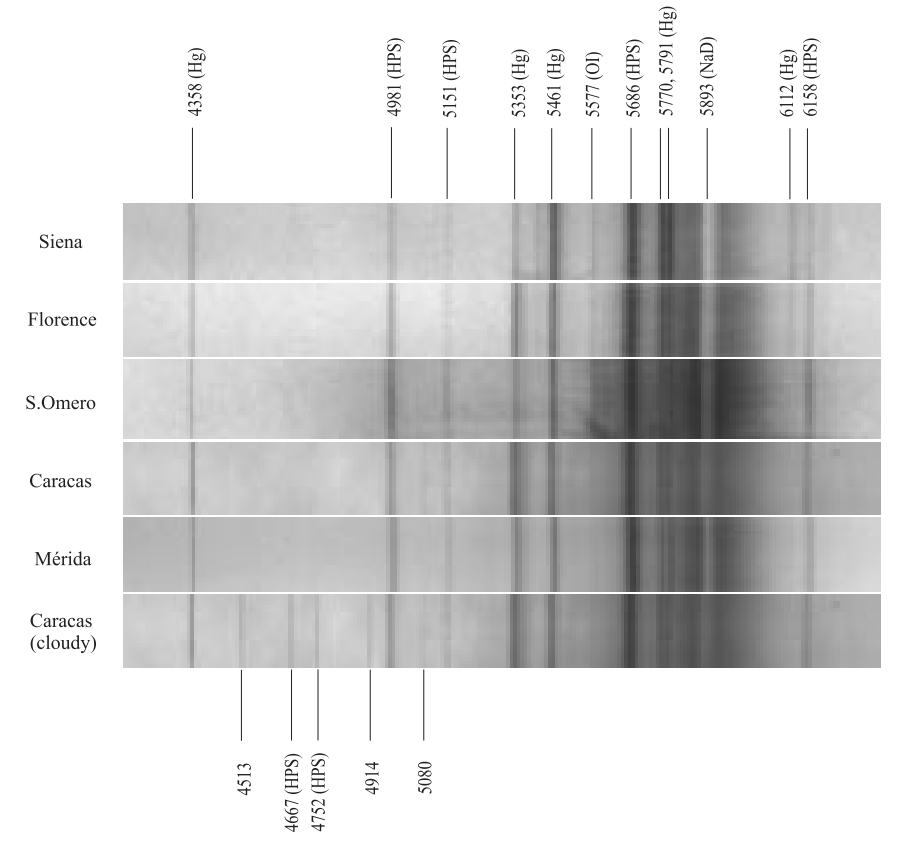

Fig. 2. Spectra of light polluted sky at selected sites in Italy and Venezuela. Wavelengths are given in Angströms. Known emission lines from artificial lighting are labelled HPS (High Pressure Sodium lamps) and Hg (Mercury Vapor lamps). All spectra were taken on Kodak T-MAX film processed for ISO 25000 and the original dispersion is $120 \AA / \mathrm{mm}$

In a developing country like Venezuela, light pollution is much lower for a given population and indeed common, incandescent lamps are still widely used in rural areas. Unfortunately, no previous sky brightness data is available and measurements at other inhabited centers are needed to determine a reliable luminosity-population relation in this country. However, comparing the values found in Caracas and Mérida with the results of Garstang (1986) for 12 Ontario cities, it is evident that city zenith brightness in Venezuela is nearly 2.5 times lower, indicating an artificial lighting output slightly over 500 lumens per capita.

In conclusion, present night sky brightness levels in populated areas are due to the higher light efficiency of modern, inadequately shielded gas discharge lamps as well as their widespread use. On the other hand, the spectral survey carried out at heavily polluted sites shows a similar, if not equal, spectral distribution (Fig. 2), produced by Mercury and High Pressure Sodium lamps.

\section{Conclusions}

Measurements of night sky brightness were carried out at selected places in Venezuela and Italy by means of a simple visual photometer. Thanks to earlier sky brightness maps of the italian territory, the light pollution increase over 25 years has been estimated at the sites tested. 
Venezuela shows lower levels of light pollution for a given population. Spectra from heavily polluted sites show that Mercury and High Pressure Sodium lamps are the main sources that contaminate the night sky.

Acknowledgements. I am profoundly indebted to V. Millucci, A. Marchini, L. Ravenni, S. Bottari, G. Quarra, P. Camaiti, R. Garosi, S. Donati, A. Pifferi and D. Herrera for their help and collaboration during the observing campaign.

\section{References}

Allen C.W., 1973, Astrophysical Quantities, third edition. The Athlone Press, London

Bertiau F.C., de Graeve E., Treanor P.J., 1973, Vatican Obs.
Publ. 1, 4, 159

Berry R., 1976, J. R. Astron. Soc. Can. 70, 3, 97

Cinzano P., 1997, Inquinamento luminoso e protezione del cielo notturno, Istituto Veneto di Scienze, Lettere ed Arti, Venezia

Falchi F., Cinzano P., 1998, in "Measuring and Modelling Light Pollution", Cinzano P. (ed.), Mem. Soc. Astron. Ital. (in press), p. 139

Gaceta Oficial de la Republica de Venezuela, No. 34.791, Decreto No. 1658, 1991

Garstang R.H., 1986, PASP 98, 364

Leinert Ch., et al., 1998, A\&AS 127, 1

Pike R., Berry R., 1978, Sky Telesc. 55, 2, 126

Schaefer B., 1998 (private communication)

Treanor P.J., Salpeter E., 1972, Observatory 92, 96

Walker M.F., 1973, PASP 85, 508 